\title{
Study of PM Removal Through Silent Discharge Type of Electric DPF Without Precious Metal Under the Condition of Room Temperature and Atmospheric Pressure
}

\author{
Minoru Chuubachi and Takeshi Nagasawa \\ Additional information is available at the end of the chapter
}

http://dx.doi.org/10.5772/53443

\section{Introduction}

For $\mathrm{CO}_{2}$ reduction and prevention of global warming, clean diesel engine vehicles have been appeared in the market. These vehicles have already cleared the severe emission regulation, such as a new post long term regulation in Japan and also due to the good combustion efficiency, their fuel efficiency are better than gasoline engine vehicle. The latest these diesel engine vehicles equip DPF (Diesel Particulate Filter) sampling PM (Particulate Matter included in the exhaust gas) and DOC (Diesel Oxidation Catalyst) which is set upstream of $\mathrm{DPF}$ and bore much precious metals such as Pt. NO in exhaust gas is converted to $\mathrm{NO}_{2}$ by DOC, and a system removing $\mathrm{PM}$ in oxygenation of the $\mathrm{NO}_{2}$ is put to practical use [1][2] However, generally the exhaust gas temperature is less than $250 \mathrm{deg}$. $\mathrm{C}$ in driving condition in the city areas, so, PM deposits in DPF without being oxidized and removed and then it may invite aggravation of the fuel efficiency from the increase of the exhaust pressure loss and an engine output power decline. For increasing exhaust gas temperature more than 250 deg. $C$, it is general that put together with a system increasing amount of fuel injection of the engine ${ }^{[3]}$, but the fuel efficiency turns worse. In addition, the increase of the pressure loss may influence on power or in the worst case, the durability of the DPF such as melting down ${ }^{[4]}[5]$. Here, there are some problems that above exhaust system need much precious metal to the DOC or DPF, the fuel efficiency turns worse, the PM consecutive removal at the low temperature is not possible. Against these problems, in this study, the Silent discharge type of electric DPF (SDeDPF) was devised originally instead of (DOC + DPF + post fuel Injection) system with unique electrode material of MFS (Metal Fiber Sheet) and Turbulent Block which makes lower speed of an exhaust gas flow. The aim of this SDeDPF is PM 
removal without using precious metal under a room temperature and an atmospheric pressure condition continually ${ }^{[6][7]}$. Finally, it contributes improving fuel consumption and $\mathrm{CO}_{2}$ reduction of the diesel engine vehicle.

\section{Basic structure of SDeDPF}

\subsection{What is silent discharge?}

The basic structure of silent discharge is shown in Fig. 1. This serves as an electric discharge cell which is a base of this research SDeDPF. The dielectrics called a barrier between the MFS (Metal Fiber Sheet) electrodes which face is inserted. Furthermore, between the dielectric and MFS electrode, the electric discharge gap (Gap d) by a spacer is prepared. If high frequency (several kilohertz) and the high voltage (several kilovolts) are added between electrodes, this whole space will be dyed a blue-purple color almost uniformly and countless minute electric discharge (micro streamer electric discharge) occurs simultaneously.

Although this electric discharge is dielectric barrier discharge or an electric discharge type only called barrier discharge, existence of a dielectric barrier has stopped progress to spark electric discharge or arc discharge. For the reason, it is also called silent discharge especially from it being the quiet electric discharge which does not emit the crashing sound at the time of electric discharge.

Since the continuation time of minute electric discharge is as short as ns (nanometer second) order, the energy transmission from an electron to ion and a gas molecule can be disregarded, and ion and a gas molecule are still room temperature.

Although the dielectric barrier discharge under atmospheric pressure condition is lowtemperature (gas temperature) operation, electron temperature is high. So since it excels in the generative capacity of activated species (radical; the atom and molecule which were rich in chemical reactivity) it is applied to an ozone generator, the surface treatment of a polymer material, disassembly of the environmental pollutant, etc. in many fields ${ }^{[8]}$. Moreover, current does not flow directly between electrodes like arc discharge or corona discharge through a barrier between electrodes, and it is the big feature that there is also little power consumption.

PM removal of SDeDPF of this research applied oxidation reaction, $\mathrm{C}$ (the carbon $\mathrm{C}$ (subject of $\mathrm{PM})$ to $\mathrm{CO}_{2}$ by the activated oxygen sorts $\left(\mathrm{O}, \mathrm{OH}, \mathrm{O}_{3}, \mathrm{NO}_{2}\right)$ generated in the electric discharge space. The component parts adopted as the electric discharge cell of SDeDPF of this research in Fig. 1 are explained concretely. The dielectrics used as a barrier is a ceramic board $\left(\mathrm{Al}_{2} \mathrm{O}_{3}\right)$ of square of $114 \mathrm{~mm}$ generally marketed, $\mathrm{t}=1 \mathrm{~mm}$ in thickness, and dielectric constant $\varepsilon=8.5$. And in order to form the gap of electric discharge space, the $1 \mathrm{~mm}$ thickness glass board was set up between the dielectric and the electric discharge electrode at the spacer. MFS (Metal Fiber Sheet,; $80 \%$ porosity with SUS material and the sintering sheet of 30 micrometers of fiber diameter) was adopted to an electrode, and it is one of the features of this research. 


\subsection{Structure of DPF System}

\subsubsection{Structure of current DPF system}

The latest current DPF system is shown in Fig. $2^{[1]}{ }^{[2]}$. Oxidation catalyst converter (DOC) which is a Channel-Flow type is arranged at the upper stream of DPF. DOC is supported by the precious metal catalyst of platinum $(\mathrm{Pt})$ etc. Then $\mathrm{NO}$ in exhaust gas is converted into $\mathrm{NO}_{2}$ at a catalyst reaction by precious metal. After DOC, DPF is arranged and when exhaust gas passes a porous ceramic wall of DPF of the Wall-Flow type, and then PM was trapped on the wall. PM (Carbon subject) trapped by DPF was oxidized to $\mathrm{CO}_{2}$ by $\mathrm{NO}_{2}$ generated by DOC and then it was exhausted as a clean gas. This system has already been put in practical use as DPF of a continuation reproduction system (ex. CRT; Continuously Regenerating Trap etc. $)^{[2]}$. However, it is necessary to maintain catalyst temperature at not less than $250 \mathrm{deg}$. $\mathrm{C}$ for a catalyst reaction. By less than it, DOC does not work well as a catalyst so that PM trapped by DPF is deposited in DPF without carrying out oxidization removal. Then pressure in DPF rises and there is a possibility of causing the durability of DPF and also the fall of engine power.

For the improvement, responding to a pressure increase in DPF, the precise fuel injection control which makes engine fuel injection amount and times increase, raises exhaust gas temperature, and promotes a catalyst reaction is needed.

\subsubsection{The preceding example of DPF applied electric discharge}

Moreover, instead of the above-mentioned CRT, many methods of PM removal by electric discharge are also proposed [9]. The latest example of a proposal that transposed DPF made from ceramics to electric discharge type of PM removal equipment is shown in Fig. 3 and Fig. $4{ }^{[10]}$ DOC is arranged like CRT in the upper stream of exhaust gas flow and the electric discharge equipment is arranged in the latter part. As Fig. 4 upper drawing, the electrode (Electrode) of metallic foil is printed on the surface of a dielectric (Dielectrics), and wavy-mesh Electrode which becomes a more pair of electrodes is set up on it and then electric discharge is generated between both these electrodes. And Fig. 4 below drawing, an exhaust gas passage is formed by laminating. It is a system which makes this space generate electric discharge and from which it removes PM. In this electric discharge structure, electric discharge becomes the streamer electric discharge into which current flows directly between both electrodes. Although the electrode is spread around the large field, electric discharge concentrates on the shortest distance part between electrodes. So it is hard to change with uniform electric discharge in the whole field and space of an exhaust passage. For the reason, generation of $\mathrm{OH}$ radical and activated oxygen sorts etc. are restricted to a part of space, so it is difficult to improve the removal performance of PM. Therefore, it seems that DOC is arranged in the upper stream of the exhaust gas flow. However, as same as the explanation of the abovementioned CRT, since DOC cannot perform $\mathrm{NO}_{2}$ generation by a catalyst reaction below at catalyst conversion temperature around $250 \mathrm{deg}$. C., it cannot perform removal of PM. Moreover, since it is electric discharge between both electrodes directly, it is thought that there are some concerns of that power consumption becomes increase due to be easy to flow 
greatly in current, generating of the crashing sound at the time of electric discharge, high temperature degradation of electrodes etc..

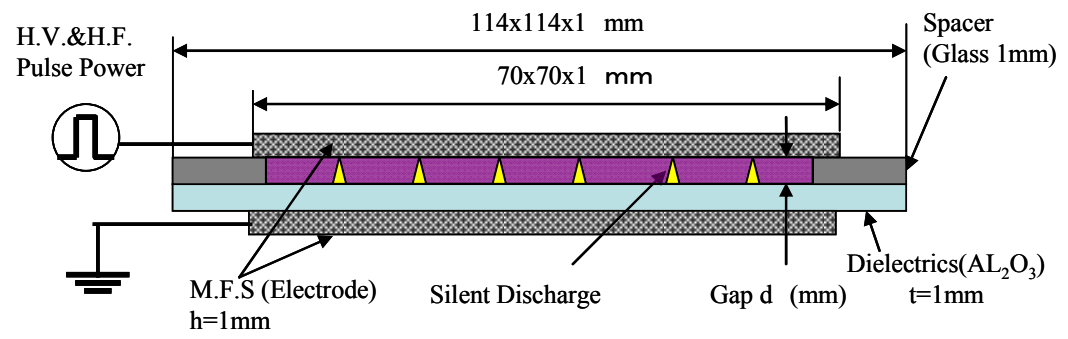

Figure 1. Basic cell of Silent electric Discharge

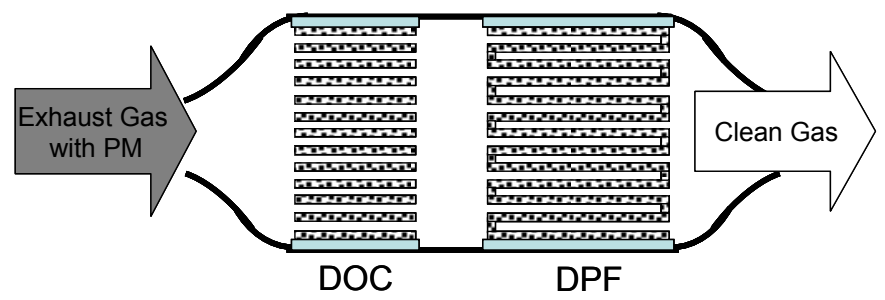

Figure 2. Current DPF system of continuously regenerating trap ${ }^{[1][2]}$

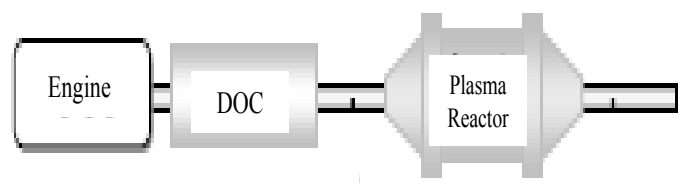

Figure 3. Example of plasma reactor system

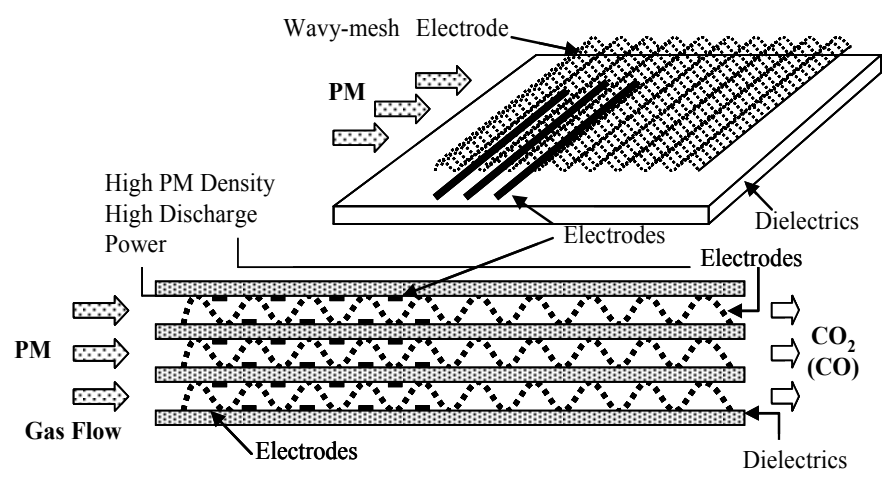

Figure 4. Example of structure of plasma reactor ${ }^{[10]}$ 


\subsubsection{Structure of silent discharge type of electric DPF (SDeDPF) of this research}

The structure of the SDeDPF final specification (Ver. 6) of this research is shown in Fig. 5 and 6. First, the front view seen from the exhaust upper stream side is shown in Fig. 5. It is the big feature that it is the Channel-Flow type with which exhaust gas passes through the electric discharge space ([7] Discharging Space) in a figure, and so that there is little pressure loss. Oxidization removal of the PM (Carbon) which passes through electric discharge space is efficiently carried out in the whole electric discharge space by $\mathrm{OH}$ radical and activated oxygen sorts $\left(\mathrm{O}, \mathrm{O}_{3}\right)$ and $\mathrm{NO}_{2}$ etc. which occurs by silent electric discharge. Since the dielectric ([1] Dielectric) is set between electrodes, large current does not flow directly so that there is little power consumption, there is little generating of the noisy sound at the time of electric discharge, as for the feature, there are also few rises in heat of an electrode part. Moreover, silent electric discharge differs from the electric discharge type example of $\mathrm{PM}$ removal equipment of above-mentioned Fig. 3 and 4, the generative capacity of $\mathrm{OH}$ radical and activated Oxygen sorts $\left(\mathrm{O}, \mathrm{O}_{3}\right)$ and $\mathrm{NO}_{2}$ etc. are high also under room temperature and atmospheric pressure conditions, without completely using the catalyst precious metals from the knowledge from other articles [11] [12] [13]. It is expectable to consider it as efficient continuous PM removal equipment.

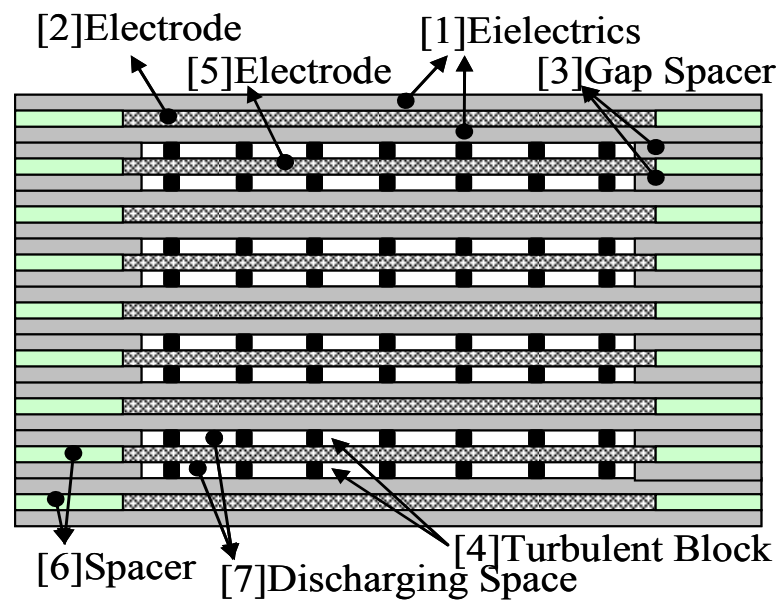

Figure 5. SDeDPF (front view)

Fig. 6 is the plan view (above) which looked at the part of the electric discharge space from the exhaust upper stream, and its AA sectional view (below). As shown in AA sectional view (below), it based the basic structure of the silent electric discharge of Fig. 1. A dielectric ([1] Dielectric), the high-voltage side electrode ([5] MFS) and the grounding side electrode ([2] MFS) form electric discharge space ([7] Discharging Space, Gap d = $1 \mathrm{~mm}$ ). The highvoltage side electrode ([5] MFS) of the central part constitutes the primitive cell (Basic Cell) is shared in two electric discharge space. Furthermore four steps of this were stacked, finally SDeDPF is constituted with eight layers of electric discharge space as shown in Fig. 5. 
(a) Plan view

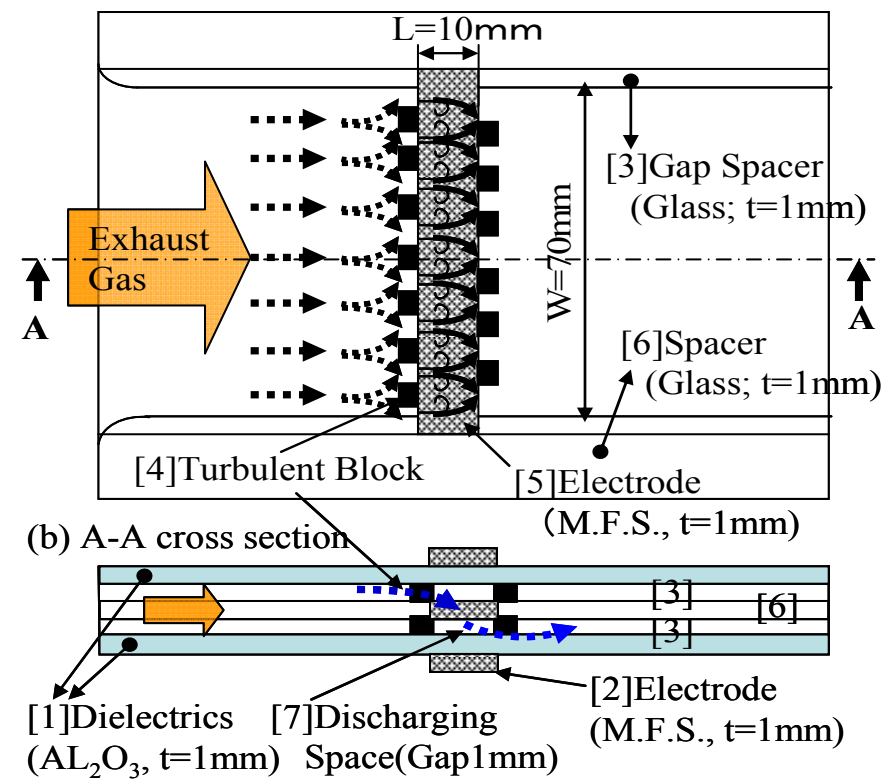

Figure 6. SDeDPF (plan view and A-A cross section view)

AS mentioned above, one of the features of SDeDPF is adoption of MFS (the sintered sheet of SUS material fiber, fiber diameter of $30 \mu \mathrm{m}, 1 \mathrm{~mm}$ in thickness, and $80 \%$ porosity) as the electrode. The aim of the adoption of MFS is utilizing the characteristics, such as reduction of the pressure loss by $80 \%$ porosity in electric discharge space, and easy excitation of the random micro streamer electric discharge by the rough surface of a sheet, and outstanding high temperature oxidation resistance.

$2^{\text {nd }}$ feature is adoption of the turbulent blocks ([4] Turbulent Block: TB). As shown in Fig.6, seven TBs are set at the upper part of an electrode and six TBs are set at the lower part of an electrode and these TBs pick up the high voltage side electrode from the upper and lower sides of it in an electric discharge space part ([7]). Aims of an adoption of these TBs are following, prevention of a deformation and a position gap and keeping stabilization of electric discharge. Moreover, finally there is an aim to improve PM removal ratio more by turbulent-flowing and a speed fall of an exhaust gas with TBs and prolonging electric discharge irradiation time to PM.

\subsection{Mechanism of PM removal}

As shown in Fig. 7, if plasma irradiated in an exhaust gas, the electron of the high energy which arises to electric discharge space in the state of high-voltage electric discharge will collide with the molecule of the oxygen contained in an exhaust gas, water, and nitrogen oxide. A mechanism as shown in Table 1, reactive oxygen species $(\mathrm{O}, \mathrm{O} 3), \mathrm{OH}$ radical and $\mathrm{N}$ 
radical in $\mathrm{NO} 2$ with high oxidation reaction nature are generated [11]. And then PM (main ingredients $\mathrm{C}$ Solid) in an exhaust gas will be oxidized and removed as $\mathrm{CO} 2$ by these reactive oxygen sorts and radicals ${ }^{[12]}$. Although $\mathrm{N} 2$ in the air has already oxidized to $\mathrm{NO}$ in the combustion process in the actual engine, in plasma discharge, $\mathrm{N} 2$ in the atmosphere is converted into NO2 of strong oxide and accelerates PM oxidization removal ${ }^{[13]}$.

Generally, compared with the conversion from NO to NO2 and the $\mathrm{O} 3$ generation by barrier discharge, the generation energy of $\mathrm{O} 3$ is far small than it of NO2. (i.e. O3 is easy to be generated far.) For generation of $\mathrm{NO} 2$, like a chemical reaction formula of $\mathrm{N}$ (NO, NO2) Radical Generation in Table 1, there is a report ${ }^{[14]}$ that $\mathrm{O}$ and $\mathrm{O} 3$ are involving greatly for generation of NO2. And like a chemical reaction formula of Activated Oxygen (O, O3) Generation in Table 1, since $\mathrm{O} 3$ is generated by work of $\mathrm{O}, \mathrm{O}$ considers again that it must be dominant in the place near room temperature. Furthermore, there is a report ${ }^{[15]}$ that energy required for the electron which arose by electric discharge to trigger the dissociative reaction of a gas molecule $(\mathrm{O} 2, \mathrm{~N} 2, \mathrm{H} 2 \mathrm{O})$, that it is 3 to 4 times as required as $\mathrm{O} 2$ and $\mathrm{H} 2 \mathrm{O}$ in the case of $\mathrm{N} 2$ and $\mathrm{N}$ radical generation speed is slow. From the generation equation of $\mathrm{O}$ and $\mathrm{OH}$ like as Table 1, $\mathrm{O}$ and $\mathrm{OH}$ were thought that it is dominant in the place near room temperature.

Like Table 1, an oxidation catalyst converts $\mathrm{N}_{2}$ and $\mathrm{NO}$ in the exhaust gas into $\mathrm{NO}_{2}$ at a catalyst reaction, and PM removal of the present diesel engine vehicle equipped with the oxidation catalyst and DPF is carrying out oxidization removal of the PM trapped in DPF by this $\mathrm{NO}_{2}$.

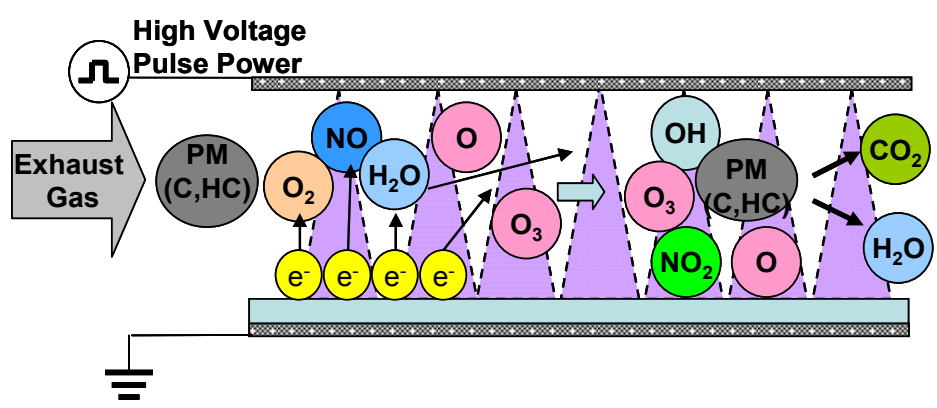

Figure 7. PM removal mechanism by Silent electric Discharge

\begin{tabular}{|l||c|}
\hline Activated Oxygen $\left(\mathrm{O}, \mathrm{O}_{3}\right)$ Generation & \multicolumn{1}{c|}{$\underline{\mathrm{OH} \text { Radical Generation }}$} \\
$\mathrm{O}_{2}+\mathrm{e} \rightarrow \mathrm{O}^{-}+\mathrm{O}+\mathrm{e}$ & $\mathrm{H}_{2} \mathrm{O}+\mathrm{e} \rightarrow \mathrm{OH}+\mathrm{H}+\mathrm{e}$ \\
$\mathrm{O}+\mathrm{O}_{2}+\mathrm{M} \rightarrow \mathrm{O}_{3}+\mathrm{M}^{*}$ & $\mathrm{O}+\mathrm{H}_{2} \mathrm{O} \rightarrow 2 \mathrm{OH}$ \\
\hline \hline$\underline{\mathrm{N}\left(\mathrm{NO}, \mathrm{NO}_{2}\right) \text { Radical Generation }}$ & $\underline{\mathrm{PM}(\mathrm{C} \text { solid }) \text { Oxidation }}$ \\
$\mathrm{N} 2+\mathrm{e} \rightarrow \mathrm{N}+\mathrm{N}+\mathrm{e}$ & $\mathrm{C}+2 \mathrm{O} \rightarrow \mathrm{CO}_{2}$ \\
$\mathrm{~N}+\mathrm{O}_{2} \rightarrow \mathrm{NO}+\mathrm{O}$ & $\mathrm{C}+2 \mathrm{OH} \rightarrow \mathrm{CO}_{2}+2 \mathrm{H}$ \\
$\mathrm{O}_{3}+\mathrm{NO} \rightarrow \mathrm{NO}_{2}+\mathrm{O}_{2}$ & $\mathrm{C}+2 \mathrm{NO}_{2} \rightarrow \mathrm{CO}_{2}+2 \mathrm{NO}$ \\
\hline
\end{tabular}

Table 1. PM (C Solid) removal mechanism by Silent electric Discharge 


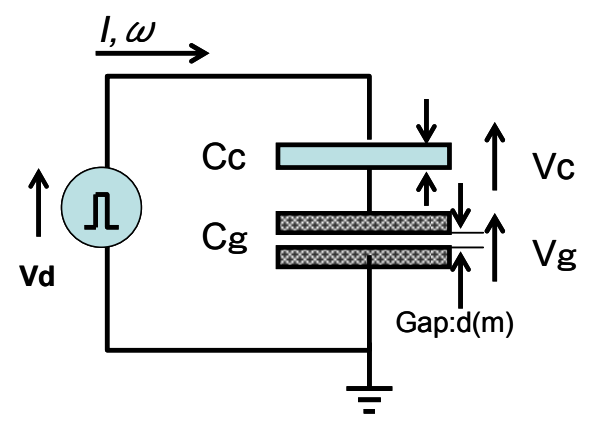

Figure 8. Real circuit of Silent electric Discharge

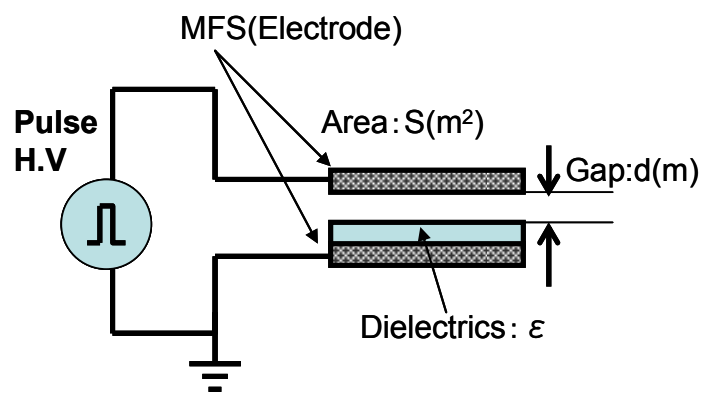

Figure 9. Equivalent circuit of Silent electric Discharge

Although for this catalyst reaction, the atmosphere temperature of not less than $250 \mathrm{deg}$. $\mathrm{C}$ is required, in silent electric discharge as mentioned above, oxidation reaction of $\mathrm{PM}$ by $\mathrm{O}, \mathrm{OH}$ or $\mathrm{O}_{3}$, and $\mathrm{NO}_{2}$ occurs at even near room temperature.

Therefore, SDeDPF is in predominance about the point which can carry out oxidization removal to the ability of continuous PM removal in the state of room temperature against that the combination of conventional (DOC+DPF ) can not perform PM removal in the state of room temperature. In order that the conventional PM removal system may solve this state, the present condition is increasing suitably the amount of engine fuel injection, raising exhaust gas temperature to not less than $250 \mathrm{deg}$. C, activating a catalyst, and promoting generation of $\mathrm{NO}_{2}$.

The generation process of $\mathrm{O}_{2} \mathrm{O}_{3}, \mathrm{OH}$ radical, and $\mathrm{N}$ radical which generated by the silent electric discharge in the inside of exhaust gas, and the process of oxidation reaction of PM (Carbon subject) is collectively shown in Table 1.

\subsection{Parameters which influence $P M$ removal performance seen from the equivalent circuit of Silent Discharge}

If the structure and the electric circuit of an electric discharge basic cell of Fig. 8 are transposed to an equivalent circuit here, it will become as it is shown in Fig. 9. 
From an equivalent circuit, the relation between applied voltage $(\mathrm{Vd})$, the voltage of a dielectric $(\mathrm{Vc})$, and the voltage between electrode gaps $(\mathrm{Vg})$ is as follows.

$$
\begin{gathered}
\mathrm{Vd}=\mathrm{Vc}+\mathrm{Vg} \\
V_{c}=\frac{I}{\omega C c} \\
V_{g}=\frac{I}{\omega C g}
\end{gathered}
$$

$I$ is the current which flows into a circuit, and omega $(\omega)$ is angular velocity $(\omega=2 \pi \mathrm{f}), \mathrm{f}$ is the power supply frequency $(\mathrm{kHz})$ and almost constant at around $5 \mathrm{kHz}$ this time. Moreover, the electric capacity of a dielectric (Cc) and an electrode gap ( $\mathrm{Cg})$, as follows, respectively.

$$
\begin{gathered}
C c=\frac{\varepsilon \varepsilon_{0} S}{t} \\
C g=\frac{\varepsilon_{0} S}{d}
\end{gathered}
$$

It is here,

$\mathrm{S}$; area $\left(\mathrm{m}^{2}\right)$ of a dielectric (Sc) and an electrode (Sg) (S and Sc are nearly equal to $\mathrm{Sg}$ )

$\mathrm{t}$; thickness of a dielectric $(\mathrm{t})$, this time fixed at $\mathrm{t}=1 \mathrm{~mm}$

d; electric discharge space gap length

$\varepsilon_{0}$; dielectric constant in a vacuum $\left(\varepsilon_{0}=8.854 \times 10^{-12} \mathrm{~F} / \mathrm{m}\right)$

$\varepsilon$; relative dielectric constant (the ceramic board used in this research is $\varepsilon=8.5$ )

Next, the following relation is realized from between a formula (2) to a formula (5)

$$
\begin{aligned}
& \frac{\mathrm{Vc}}{\mathrm{t}}=\frac{I}{\omega \varepsilon \varepsilon_{0} S} \\
& \frac{\mathrm{Vg}}{\mathrm{d}}=\frac{I}{\omega \varepsilon_{0} S}
\end{aligned}
$$

A formula (6) and a formula (7) are showing the electric field strength in a dielectric and electric discharge space. In order to remove PM efficiently through the silent electric discharge which is the purpose of this research, it is necessary to raise the electric field strength $(\mathrm{Vg} / \mathrm{d})$ in electric discharge space. Therefore, in order to enlarge $\mathrm{Vg}$ from a formula (1) first, it is direct to enlarge the applied voltage Vd itself. However, since it is considered as $\mathrm{Vd}$ regularity this time, it is required to make Vc small. From a formula (2) and a formula (4), if $I$ and $\omega$ (i.e. f) are fixed case , in order to make Cc larger, it is more effective to enlarge relative dielectric constant $\varepsilon$. Although the ceramic board (AL2 O3) $\varepsilon=8.5$ is used this time, if 
the titanium dioxide ( $\mathrm{TiO} 2) \varepsilon=86$ and barium titanate $\left(\mathrm{BaTiO}_{3}\right) \varepsilon=2900$, etc. are used, it turns out that improvement in still larger electric field strength is expectable. However, this time research was advanced using the cheap ceramic board which is generally marketed. Moreover, from a formula (7), when Vg is fixed voltage, it turns out that it is effective to make d small and to make electric discharge electrode area $S$ small. From these results of analyzing parameters, the evaluation of discharging characteristics of the electric discharge cell and SDeDPF as opposed to change of the applied voltage Vd were carried out. Then it was considered that discharge gap $\mathrm{d}$ and the area of discharging electrode $\mathrm{S}$ which influence the performance of electric discharge greatly were important parameters for the evaluation.

\section{Experimental devices and method}

\subsection{Experiment evaluation devices of discharging characteristic with basic structure of SDeDPF}

The evaluation equipment of the basic cell of SDeDPF is shown in Fig. 10. Electric supply equipment (High Voltage Pulse Power Supply) is PPS-4000S type custom-made item made from ECG-KOKUSAI. The voltage set up with electric supply equipment from former power supply $\mathrm{AC} 100 \mathrm{~V}$ is amplified as primary voltage to the maximum voltage of $2 \mathrm{kV}$, the maximum supply current of $150 \mathrm{~mA}$, and the maximum frequency of $5 \mathrm{kHz}$, and electric discharge is generated by eventually applying the high frequency and the high voltage of a maximum of $25 \mathrm{kVpp}$ (secondary voltage; i.e. voltage between $\mathrm{B}$ and F) to the test sample. As a formula (7), since electric field strength is in discharge current and proportionality relation, in order to measure the current (Ig) between $\mathrm{D}$ and $\mathrm{E}$ as Fig. 10, $1.5 \Omega$ shunt resistance is arranged and current conversion from the amplitude measurement in an oscilloscope is carried out. The size of the discharge current (Ig) is made into the alternative characteristic of electric field strength. A measurement condition is in room temperature and a static state and the preset value of electric supply equipment is the maximum voltage of $0.5 \mathrm{kV}$ and the frequency of $4.8 \mathrm{kHz}$. When Ver. 6 of the final specification was in an electric discharge state, reduction level of the current value (Ig) was seen about $5 \%$ by the result of having passed $2 \mathrm{~m}^{3} / \mathrm{h}$ air flow rate as a dynamic state at room temperature. It was judged that there was no big influence in evaluating the characteristic of basic structure by static condition with the equipment like Fig. 10.

\subsection{Characteristic of high voltage pulse power supply}

The result that have been investigated the characteristic of the output voltage of the High Voltage Pulse Power Supply (HVPPS) is shown in Fig.11 and 12. The oscilloscope was directly connected to the last output end (B point and F point in Fig.10) of the HVPPS and the characteristic of voltage and current of pulse power supply itself were measured. Power supply frequency was fixed to $\mathrm{f}=5.0 \mathrm{kHz}$ which is the maximum of specification of this device and the change of power supply(1st order = Ep) current and the relation of output (2nd order ) voltage are shown in Fig.11. But $150 \mathrm{~mA}$ is the maximum supply current on specification, the supplied current serves as a limit by a security apparatus at $130 \mathrm{~mA}$. 
Therefore maximum output voltage is $13 \mathrm{kVpp}$ at $0.35 \mathrm{kv}$ voltage and $130 \mathrm{~mA}$ of primary current arranged by Pulse Power Supply. The result in case of changing power supply frequency with fixing the primary voltage $0.5 \mathrm{kV}$ is shown in Fig.12. In this device, the limit that an electric discharge state is stably maintainable was set to about $4.8 \mathrm{kHz}$ and then he output (2nd order) voltage at this time was $24 \mathrm{kVpp}$ without depending on frequency. The voltage waveform (from 23.2 to $24 \mathrm{kVpp}$ ) outputted from the Pulse Power Supply when it sets to the primary voltage of $0.5 \mathrm{kV}$ and frequency $4.8 \mathrm{kHz}$ is shown in Fig.13 and 14 .

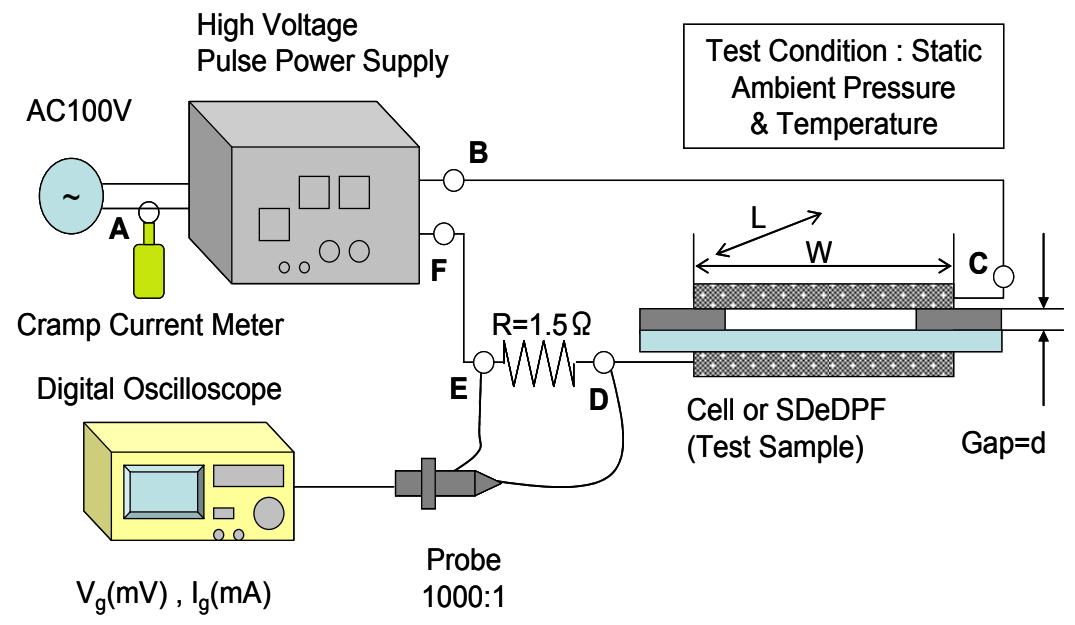

Figure 10. Test equipment for discharging characteristic of SDeDPF or Cell

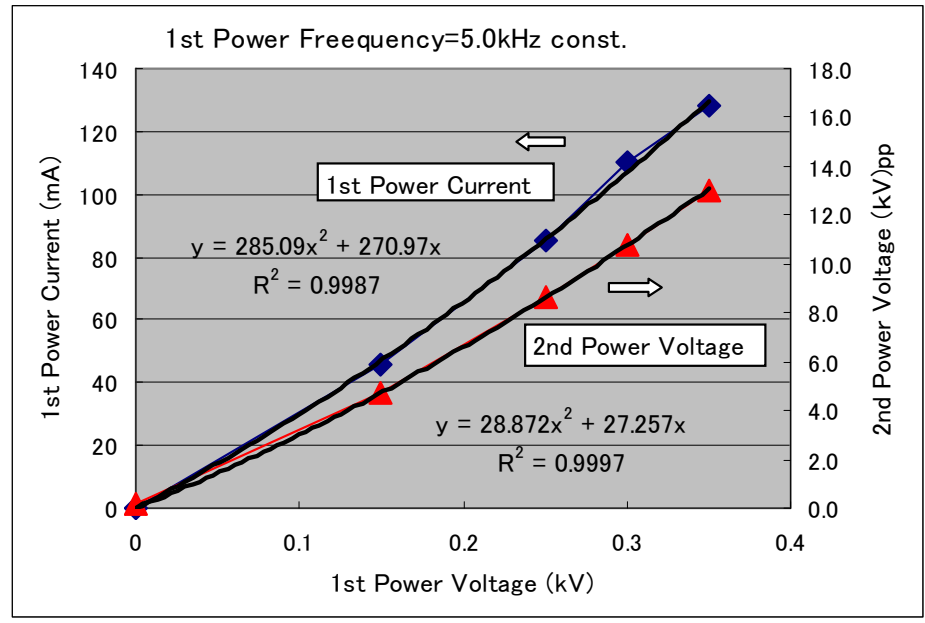

Figure 11. Characteristic of Power Supply $(\mathrm{f}=5.0 \mathrm{kHz})$ 


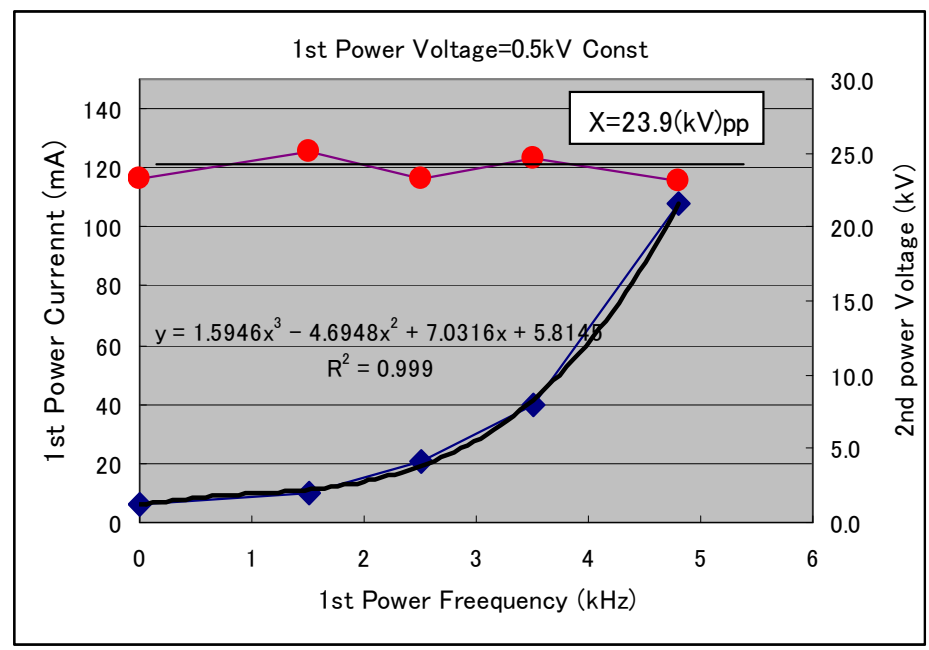

Figure 12. Characteristic of Power Supply $\left(E_{\mathrm{p}}=0.5 \mathrm{kV}\right)$

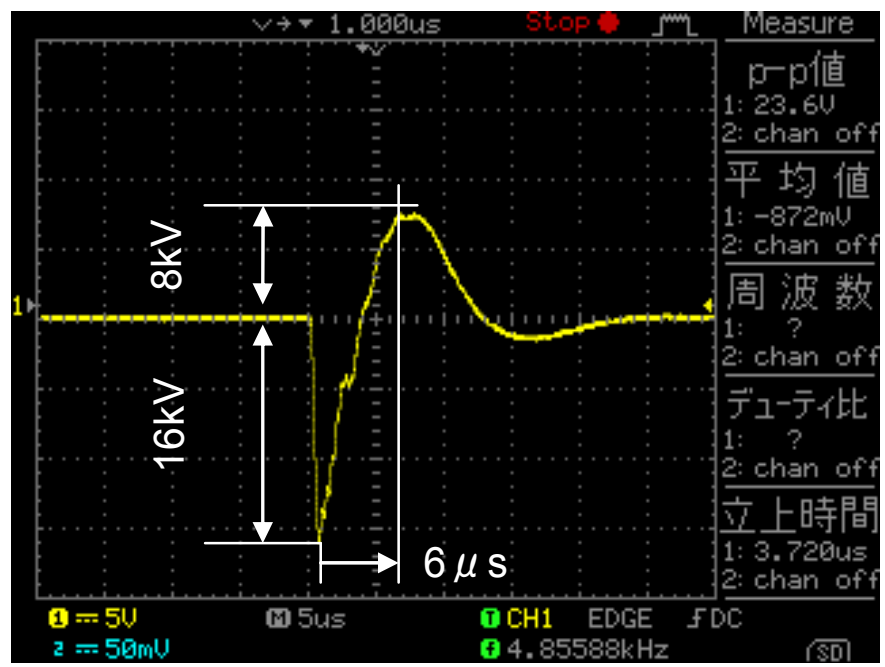

Figure 13. Detail of voltage wave of applied voltage $(\mathrm{Vd}=23.9 \mathrm{kVpp})$

Although this Pulse Power Supply (PPS) can switch the polarity (plus or minus) of a pulse arbitrarily, in this research, minus pulse output has been applied. The detail of voltage wave of the impressed voltage (out put voltage from PPS) is shown in Fig. 13, it have reached in $6 \mu \mathrm{s}$ from (-) peak $16 \mathrm{kV}$ to $(+)$ peak $8 \mathrm{kV}$. And then the Voltage on SDeDPF is $12 \mathrm{kVpp}$ as shown in Fig.14 which is a similar wave to Fig.13. If the above result is summarized, it will become as it is shown in Table 2. With the setting voltage (Ep) and frequency (f) in the PPS, the voltage of $\mathrm{Vd}(\mathrm{kVpp})$ will be impressed to SDeDPF. Voltage impressed to SDeDPF is indicated to expressing by $\mathrm{Vd}(\mathrm{kVpp})$ after this. 


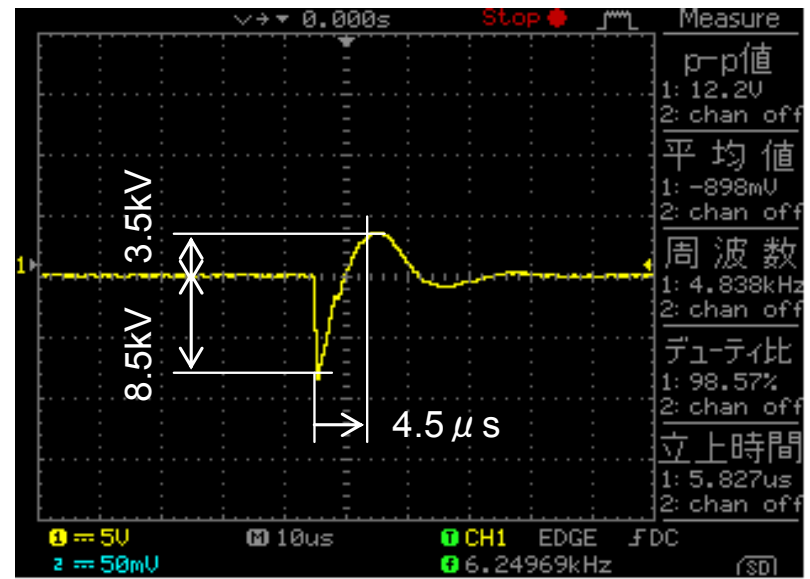

Figure 14. Detail of voltage wave on $\mathrm{SDeDPF}(\mathrm{Vd}=23.9 \mathrm{kVpp})$

\begin{tabular}{|l|l||c|c|c|c|c|}
\hline $\begin{array}{l}\text { Setting voltage with } \\
\text { Pulse Power Supply }\end{array}$ & $\begin{array}{l}\text { Setting voltage: } \\
\text { Ep (kV) }\end{array}$ & 0.00 & 0.15 & 0.25 & 0.35 & 0.50 \\
\cline { 2 - 7 } & $\begin{array}{l}\text { Setting Feq.: } \\
\mathrm{f}(\mathrm{kHz})\end{array}$ & 0.0 & 5.0 & 5.0 & 5.0 & 4.8 \\
\hline \hline $\begin{array}{l}\text { Applied Voltage to SDeDPF } \\
\text { Vd (kV)pp }\end{array}$ & 0.0 & 4.7 & 8.7 & 13.1 & 23.9 \\
\hline
\end{tabular}

Table 2. Relationship between setting voltage by power supplying device and added voltage on SDeDP

\section{Test result}

\subsection{Test result of discharging characteristic with basic cell and SDeDPF structure}

\subsubsection{Influence of gap length}

The influence of gap length d exerted on electric discharge with the basic cell structure of Fig. 1 in the equipment of Fig. 10 was shown in Fig. 15. The discharge current Ig showed the maximum between $\mathrm{d}=1 \mathrm{~mm}$ to $2 \mathrm{~mm}$. Moreover, looking hard at the state of electric discharge, at not less than $\mathrm{d}=2 \mathrm{~mm}$, all the dotted micro discharge becomes strong a spark discharge. In $\mathrm{d}=3 \mathrm{~mm}$, the stronger spark discharge in the shortest distance part between electrodes break out and in $\mathrm{d}=5 \mathrm{~mm}$, the creeping discharge which the discharge current flows on the spacer wall surface which serves as the shortest distance further are seen and also the noise of the spark discharge became larger. The state of the electric discharge state in between $d=1 \mathrm{~mm}$ to $2 \mathrm{~mm}$ is very stable. In this research of first stage, the basic gap length of SDeDPF was set $\mathrm{d}=1 \mathrm{~mm}$ constant which had the maximum discharge current $\mathrm{Ig}$ with impressed voltage of $13.1 \mathrm{kVpp}$, and that was considered the power saving by $13.1 \mathrm{kVpp}$ rather than $23.9 \mathrm{kVpp}$. 


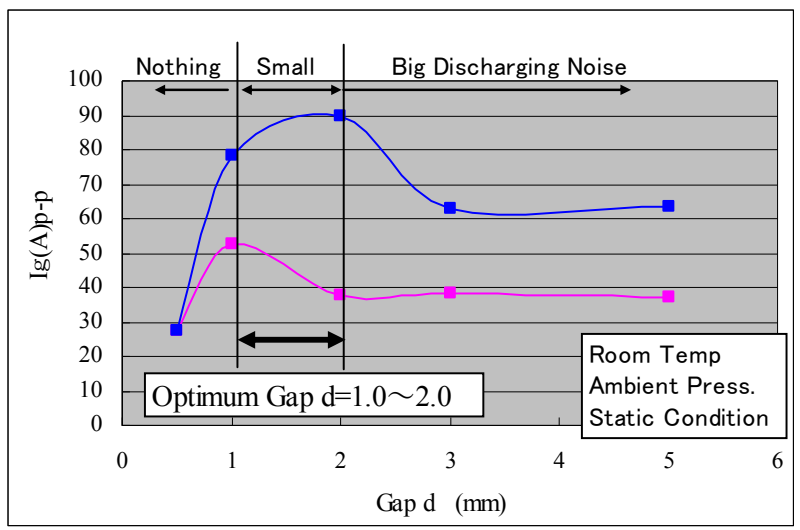

Figure 15. Influence of Gap

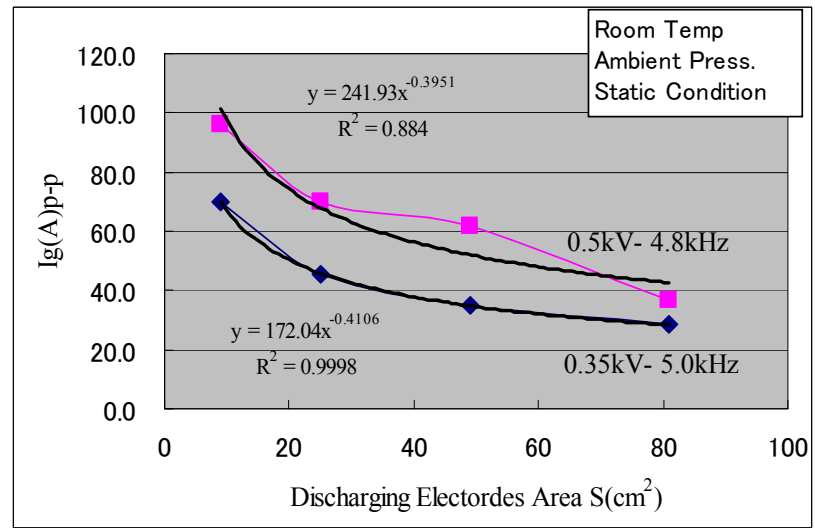

Figure 16. Influence of Electrode Area

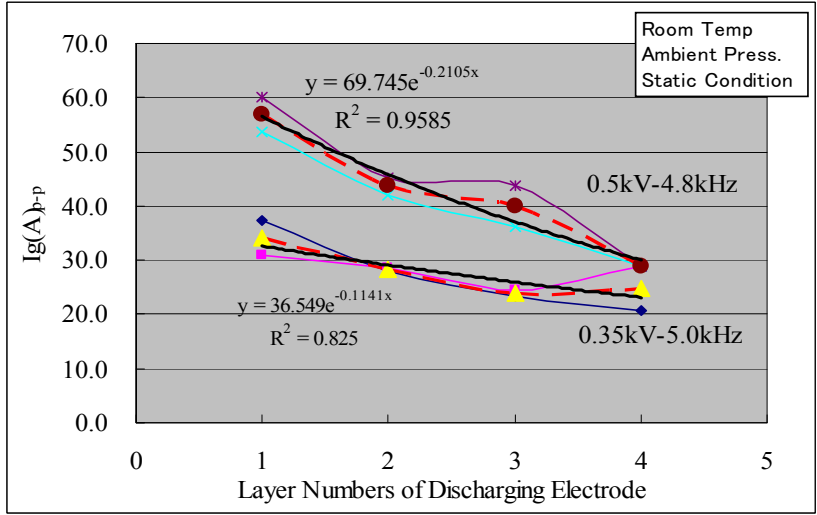

Figure 17. Influence of Layered Numbers of Electrodes (Total Area) 


\begin{tabular}{|c||c|c|c|c|c|c|c|}
\hline Type & $\begin{array}{c}\text { SDeDPF } \\
\text { Cell Layers }\end{array}$ & $\begin{array}{c}\text { Discharge } \\
\text { Gap d } \\
(\mathrm{mm})\end{array}$ & $\begin{array}{c}\text { Electrode } \\
\text { Position } \\
\mathbf{D}(\mathrm{mm})\end{array}$ & $\begin{array}{c}\text { Electrode } \\
\text { Length } \\
\mathbf{L}(\mathrm{mm})\end{array}$ & $\begin{array}{c}\text { Total } \\
\text { Electrode } \\
\text { Area } \mathbf{S}\left(\mathrm{cm}^{2}\right)\end{array}$ & $\begin{array}{c}\text { Electrode } \\
\text { Position } \\
\text { Numbers }\end{array}$ & $\begin{array}{c}\text { Turbulent } \\
\text { Blocks }\end{array}$ \\
\hline \hline Ver.2 & 2 & 1.0 & 22 & 70 & 98 & 1 & No \\
\hline Ver.3 & 4 & 1.0 & 47 & 20 & 56 & 1 & No \\
\hline Ver.5 & 8 & 1.0 & 52 & 10 & 56 & 1 & No \\
\hline Ver.6 & 8 & 1.0 & 52 & 10 & $56(50.6)$ & 1 & With \\
\hline
\end{tabular}

Table 3. Each Type of SDeDPF for Evaluation of PM Removal

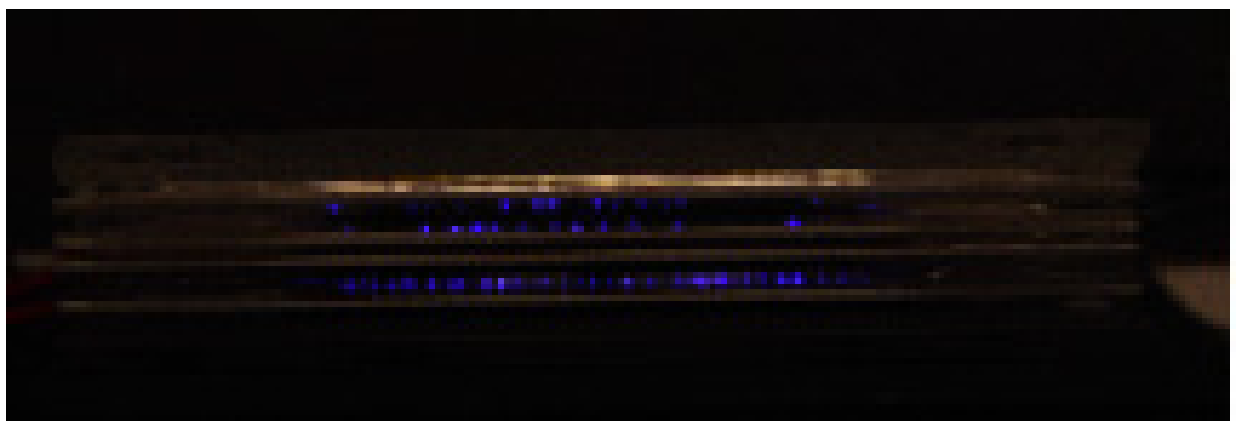

(Violet-bluish Micro-streamer Discharge, white part is lighting)

Figure 18. Example of Discharging of SDeDPF (Ver.3 Vd=13.1kVpp)

\subsubsection{Influence of discharging electrode area}

With the equipment of Fig.10, the result of having checked the relation of electrode area (S) and the discharge current (Ig) is shown in Fig. 16. Four variations of discharging electrode

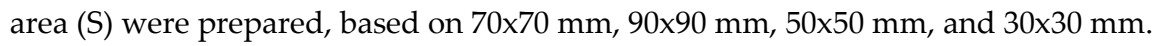

Discharge current (Ig) is converted from voltage measurement of the oscilloscope in the 1.5 $\Omega$ shunt resistance between $\mathrm{D}$ and $\mathrm{E}$ of Fig. 10 .

As shown in Fig. 16, if the discharging electrode area (S) becomes large, the discharge current (Ig) will decrease. It is the reason that as understanding from a formula (7), if the discharging electrode area (S) increase, then the electric field strength will fall, and sufficient discharge current $(\mathrm{Ig})$ is not acquired. In order to secure an exhaust pressure loss equivalent to the present DPF made from ceramics, it turns out that it is necessary to reduce the total area of electrodes. Because the electric field strength falls, if it does not change the frontage size (W) of SDeDPF entrance, it is necessary to increase the number of stages of the electric discharge basic cell which will be laminated.

\subsubsection{Influence of electrode layer numbers}

As mentioned above, it is expected that the one which has larger discharge current (Ig) has the higher PM removal performance. If the lamination number of sheets of an electrode 
becomes increase (the total electrode area increase), electric field strength will fall from a formula (7) and then PM removal performance declines. Fig. 17 shows the relation of the number of lamination stages and the discharge current (Ig). It is the result of laminating $\mathrm{W}=$ $70 \mathrm{~mm}$ and $\mathrm{L}=70$-mm MFS electrode from 1 to 4 layers. If the discharge current (Ig ) will be four layers, it will be reduced by half compared with one layer. If the frontage of $\mathrm{W}=70 \mathrm{~mm}$ is fixed, and for making discharge current equivalent, it necessary to set $\mathrm{L}$ to one half. Furthermore, an exhaust pressure loss is considered, for considering it as eight layers, it is necessary to set L to one fourth. Ver. 2 to Ver. 6 is manufactured as specification which evaluates PM removal performance to the above electric discharge characteristic as shown in the examination result of an influence factor to the table 2. Ver. 6 was made into the last specification of this stage.

Fig. 18 is an example of the state of discharging of SDeDPF type of Ver.3 which $\mathrm{Vd}=13.1 \mathrm{kV}$ p was impressed. Violet-bluish many micro-streamer discharge were seen.

\subsubsection{Test Equipment of PM removal mechanism analysis}

Until now, the parameter which influences PM removal was clarified based on PM removal mechanism by the silent electric discharge described by Section 2.3 and 2.4 and improvement in PM removal ratio has been aimed at by various kinds of variation trial productions. As a result, PM removal ratio which was almost quite high as prediction and examination has been attained.

However, it needed to verify whether really such a PM removal mechanism would act, and the verification was performed with experimental devices as shown in Fig.19. PM (carbon subject) which supplied from PM generating equipment (PM Generator) was oxidized from $\mathrm{C}$ to $\mathrm{CO}_{2}$ or $\mathrm{CO}$ by $\mathrm{O}, \mathrm{O}_{3}, \mathrm{OH}$ and $\mathrm{N}$ radical which were strong activated oxygen sorts and generated by the plasma which occurred in SDeDPF. And then in the exit of SDeDPF, it is measured how $\mathrm{CO}$ or $\mathrm{CO}_{2}$ concentration changes.

PM generating equipment (PM Generator) is mentioned in detail at next section 4.3 and high frequency and high voltage supply unit (Pulse Power Supply) are completely the same as what was explained in Fig.10. The exclusive probe of $\mathrm{CO}$ and $\mathrm{CO}_{2}$ concentration measuring device (IAQ Monitor Model2211 made from CO\&CO 2 Meter; KANOMAX) is inserted in the exit of SDeDPF, and as opposed to change of the applied voltage to SDeDPF , the change of $\mathrm{CO}$ and $\mathrm{CO}_{2}$ concentration is measured.

\subsection{Verification result of PM removal mechanism}

As a verification of $\mathrm{PM}$ removal mechanism, the measurement result of concentration change of $\mathrm{CO}$ and $\mathrm{CO}_{2}$ as opposed to the applied voltage to SDeDPF is shown in Fig. 20. Although $\mathrm{CO} \& \mathrm{CO}_{2}$ of the entrance of SDeDPF is the concentration of the usual ambient level, it seems that a little since an exit is in the state where PM is supplied from PM generating equipment, $\mathrm{CO}_{2}$ by that of combustion are going up. As the base of this point, the concentration change of $\mathrm{CO}_{2}$ and $\mathrm{CO}$ was measured when the applied voltage to $\mathrm{SDeDPF}$ is raised. 
It has confirmed $\mathrm{CO}_{2}$ concentration rising, and $\mathrm{C}$ oxidizing to $\mathrm{CO}_{2}$ as opposed to increasing the applied voltage $\mathrm{Vd}$. In particular, in maximum applied voltage $\mathrm{Vd}=23.9 \mathrm{kVpp}$ of this equipment, the rapid increase in $\mathrm{CO}_{2}$ and also $\mathrm{CO}$ can obtain the data of a rapid upward tendency, and can guess that the oxidation reaction from $\mathrm{C}$ to $\mathrm{CO}_{2}$ or $\mathrm{CO}$ is advancing violently.

From this result, it was judged that between the applied voltage $\mathrm{Vd}$ on SDeDPF and concentration change of $\mathrm{CO}_{2}$ and $\mathrm{CO}$ was interlocking closely, and that the mechanism by which PM was oxidized and removed with a strong activated oxygen sorts by silent electric discharge was supported.

In the applied voltage $\mathrm{Vd}$ from 0 to $23.9 \mathrm{kVpp}$, the average increase of $\mathrm{CO}_{2}$ concentration is about $10 \mathrm{ppm}$ (from $390 \mathrm{ppm}$ to $400 \mathrm{ppm}$ ), and similarly although the average increases of $\mathrm{CO}$ concentration are few, it is about $1 \mathrm{ppm}$ (from 0 to $1 \mathrm{ppm}$ ).

Furthermore, in order to support the above-mentioned change of state, the increase in mass as opposed to increase of $\mathrm{CO}_{2}$ and $\mathrm{CO}$ concentration was calculated by using the gas equation of an equation (8). The content of Carbon (C) which was a main ingredients of PM was further calculated from those molecular weight ratios.

$$
\mathrm{V}=(\mathrm{w} / \mathrm{M}) \mathrm{RT} / \mathrm{P}
$$

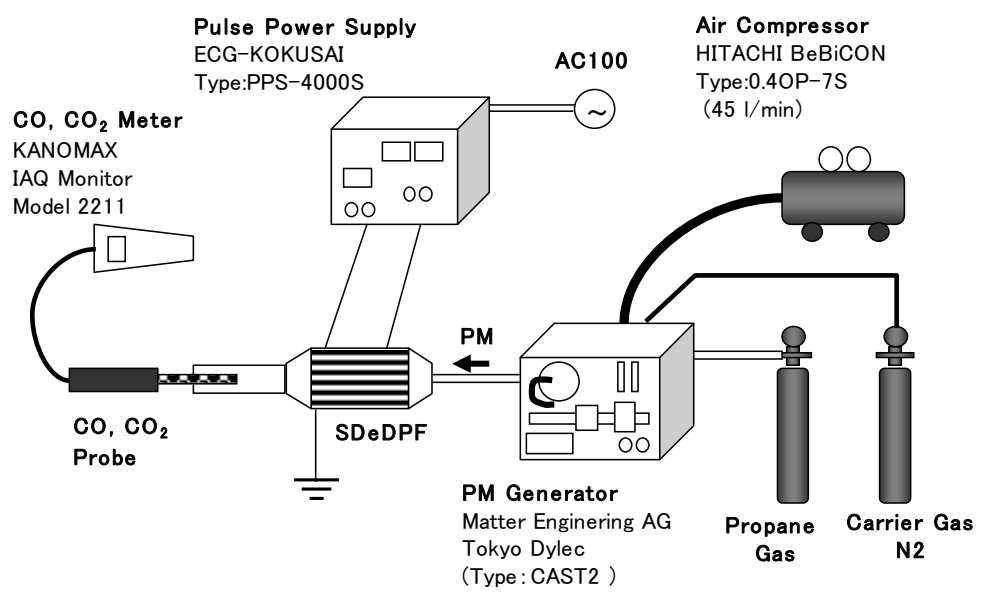

Figure 19. Test equipment of Measuring $\mathrm{CO}_{2} \& \mathrm{CO}$ conversion from $\mathrm{C}$ (SDeDPF; Ver.6)

Here,

$\mathrm{P}$ : pressure (atom) $=1, \mathrm{~V}$ : volume (liter), w: mass of $\mathrm{CO}_{2}$ or $\mathrm{CO}$,

$\mathrm{M}$ : the molecular weight of $\mathrm{CO}(28 \mathrm{~g})$ or $\mathrm{CO}_{2}(44 \mathrm{~g})$, R: constant gas factor $=0.0821$,

T: absolute temperature $(K)=25+273.15=298.15$ (constant as a room temperature)

Since $1 \mathrm{~m}^{3}$ is 1000 liters and the volume ratio of $1 / 1000000$ is set to $1 \mathrm{ppm}$, the volume of 10 ppm $\mathrm{CO}_{2}$ is set to $\mathrm{V}_{\mathrm{CO} 2}=10 \times 10^{-3}$ (liter) from following calculation. 


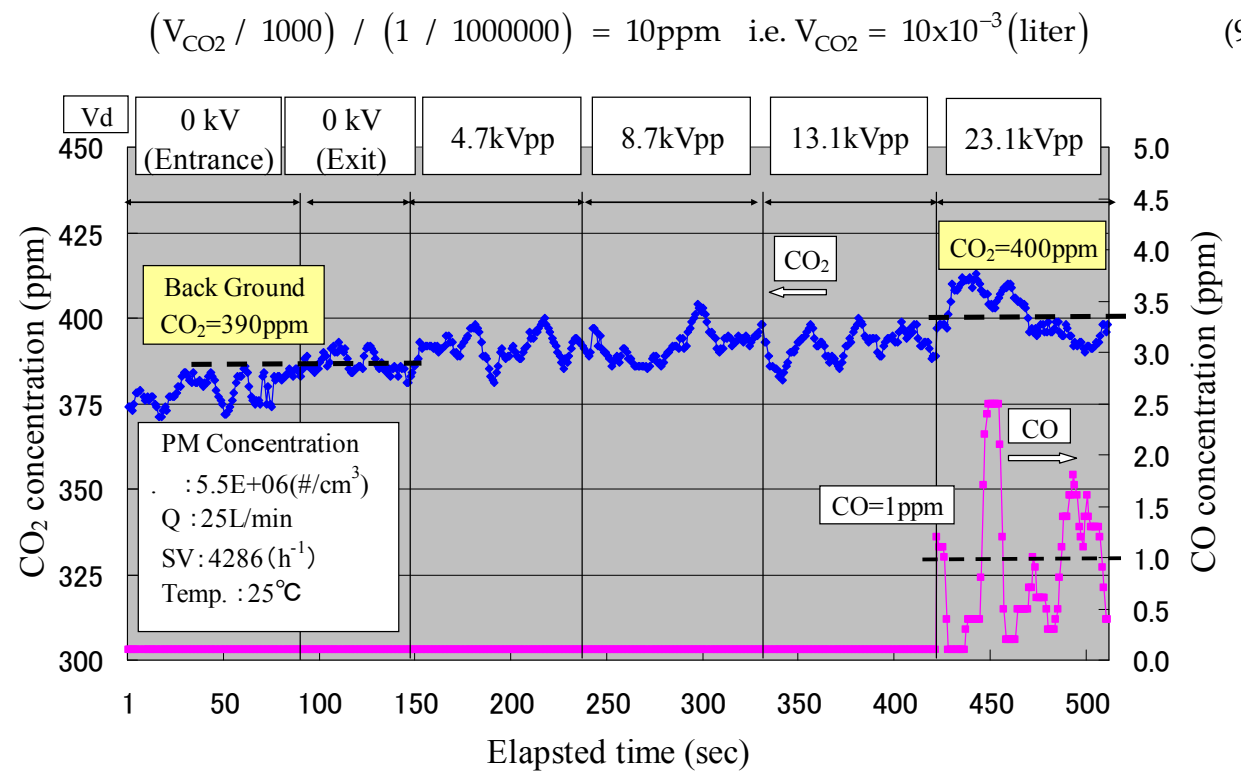

Figure 20. Verification Test of Changing from $\mathrm{C}$ to $\mathrm{CO}$ and $\mathrm{CO}_{2}$ by Silent Discharge

Similarly, the volume of $1 \mathrm{ppm} \mathrm{CO}$ is set to $\mathrm{V}_{\mathrm{CO}}=1 \times 10^{-3}$ (liter) from following calculation.

$$
\left(\mathrm{V}_{\mathrm{CO}} / 1000\right) /(1 / 1000000)=1 \mathrm{ppm} \text { i.e. } \mathrm{V}_{\mathrm{CO}}=1 \times 10-3 \text { (liter) }
$$

When these results of calculation (10) and (11) are calculated by a formula (8), increase mass of $\mathrm{CO}_{2}$ : wCO2 is following.

$10 \times 10^{-3}($ liter $)=(\mathrm{WCO} / 44) \times 0.0821 \times 298.15 / 1.0 \quad$ i.e. $\quad \mathrm{WCO} 2=(10 \times 10-3 \times 44) / 0.0821 \times 298.15=$ $17.98 \times 10^{-3}(\mathrm{~g})$

Therefore, the content of $\mathrm{C}$ is from a molecular weight ratio,

$$
17.98 \times 10^{-3} \mathrm{x}(12 / 44)=4.9 \times 10^{-3}(\mathrm{~g})
$$

Similarly, an increase mass of CO: wco is following.

$1.0 \times 10^{-3}($ liter $)=(\mathrm{wCO} / 28) \times 0.0821 \times 298.15 / 1.0 \quad$ i. e. $\mathrm{WCO}=\left(1.0 \times 10^{-3} \times 22\right) / 0.0821 \times 298.15=$ $1.15 \times 10^{-3}(\mathrm{~g})$

Therefore, the content of $\mathrm{C}$ is from a molecular weight ratio,

$$
1.15 \times 10^{-3} \times(12 / 28)=0.49 \times 10^{-3}(\mathrm{~g})
$$

The increase sum total of $\mathrm{C}$ is set to $5.39 \times 10^{-3}$ ( $\mathrm{g}$ ) from the above calculation result (11) and (12). Since the premise is calculation by of $1 \mathrm{~m}^{3}$, this is replaced with $5.39 \times 10^{-3}\left(\mathrm{~g} / \mathrm{m}^{3}\right)$. 
On the other hand, the result of the amount of mass change directly measured with PM number concentration analyzer at the time of silent electric discharge with Ver.6 is $5.48 \times 10^{-3}$ $\left(\mathrm{g} / \mathrm{m}^{3}\right)$. Therefore, it has confirmed certain similarity between the calculated value by the gas equation of state (8) and the direct measured value with PM number concentration analyzer. From this result, it was proved quantitatively that the concentration change of $\mathrm{CO}_{2}$ and $\mathrm{CO}$ at the time of the electric discharge respond to PM oxidizing and increasing, and moreover I think certainly that PM removal mechanism by silent electric discharge was supported quantitatively.

\subsection{Test Equipment for PM Supply System (PPM) and PM Removal Evaluation}

Test Equipment of PPS and PM Removal Evaluation is shown in Fig. 21. A fixed concentration PM which was generated by PM Generator (combustion particulate generating equipment) was supplied to SDeDPF. Raw Gas Dilution \& Engine Exhaust Particle Sizer (an exhaust gas particulate number counting system) measures the change of PM concentration as opposed to the change of the high frequency and the high voltage which was impressed to SDeDPF and evaluates the PM removal rate form the decreasing change of the PM concentration. PM is generated when adjusted $\mathrm{N}_{2}$, the air content and the propane gas were mixed and burned in PM Generator. Here, PM concentration means the particulate number $\left(\# / \mathrm{cm}^{3}\right)$ which contained per sampling gas $1 \mathrm{~cm}^{3}$. The amount of supplying gas is 0.25 $\mathrm{L} / \mathrm{min}\left(1.5 \mathrm{~m}^{3} / \mathrm{h}\right)$ and SV of SDeDPF at this time is a maximum of $4286\left(\mathrm{~h}^{-1}\right)$.

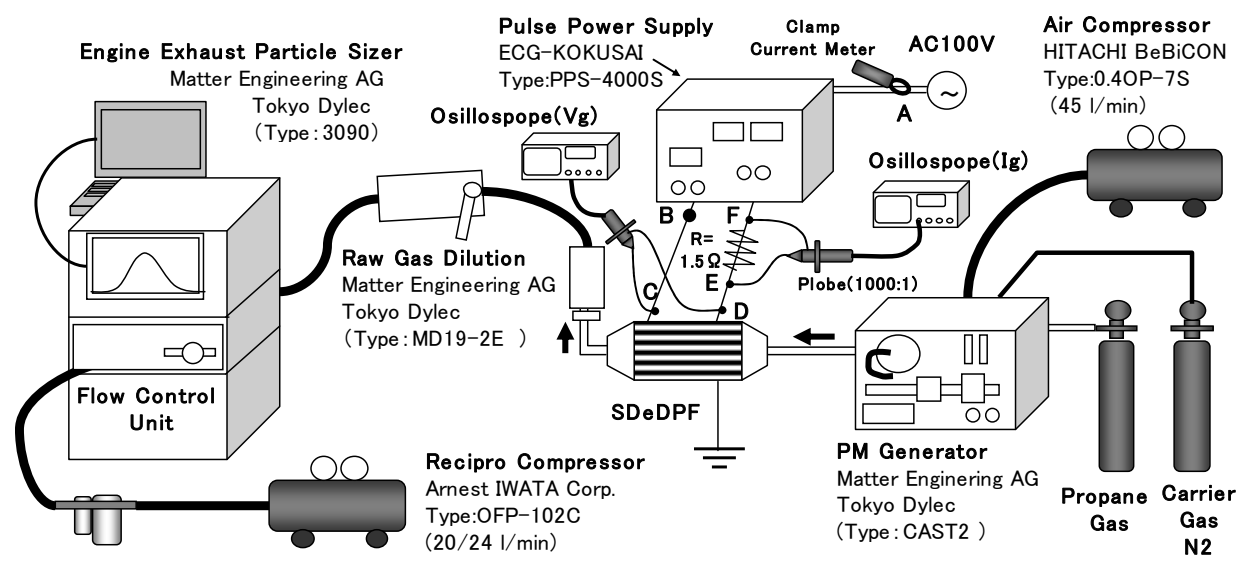

Figure 21. Test equipment for PM Supply System and PM Removal Evaluation

Fig. 22, 23, 24 and 25 are coincidence measurement results of the voltage (Vg) (between C and D in Fig. 21) and discharge current (Ig) (between E and F in Fig. 21) which occurs in SDeDPF when Vd $=23.9 \mathrm{kVpp}$ is impressed by a Pulse Power Supply in the measurement circuit of Fig. 21. As shown in Fig. 22, the charge-and-discharge current of the corresponding phase in sync with the frequency of $4.8 \mathrm{kHz}$ of service voltage has occurred in pulse. Fig. 23 and 24 are the waveform which expanded Fig. 22. Each two of Non-discharging period and Discharging period ${ }^{[16][17]}$ exist in one cycle, respectively. 
Furthermore, the waveform which expanded Fig. 24 is shown in Fig. 25. At first discharge, the minus pulse voltage $\mathrm{Vg}$ rises and after 0.5 microsecond of non-discharging periods, charge-and-discharge current (a max. of $157 \mathrm{App}$ ) generates in the pulse of high frequency at the starting discharge Voltage $\mathrm{Vs}=-2.5 \mathrm{kV}$ and then the discharging period continues for 0.8 microsecond. Moreover the 2nd discharging period has passed the non-discharging period for 3.6 microseconds since the 1st discharging period as shown in Fig. 24, in charge-and-discharge current (a max. of $73 \mathrm{App}$ ), the pulse of high frequency continues for 4 microseconds.

Then the current measured with clamp meter was 0.88A in the AC100V line in front of the PPS unit at this time, so it was confirmed that the electric power was $88 \mathrm{~W}$ including the PPS and SDeDPF.

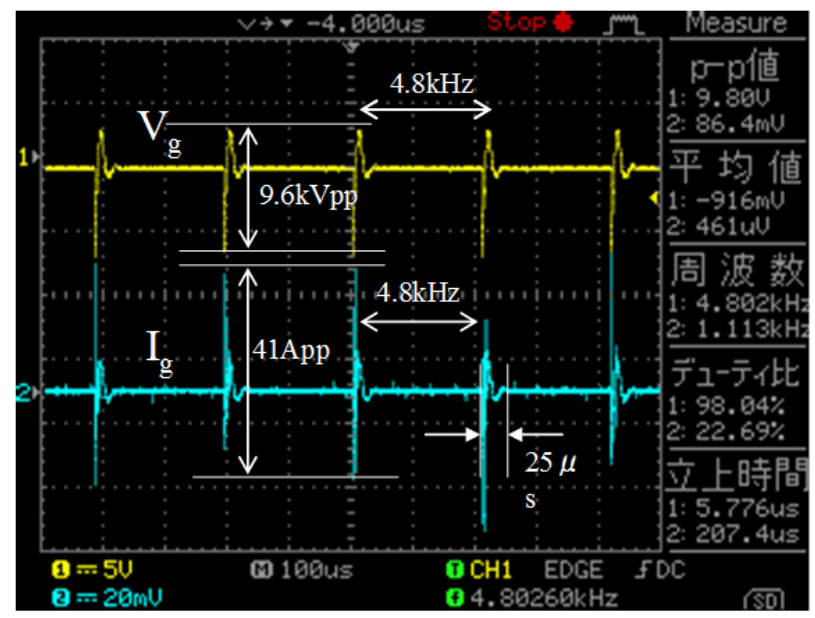

Figure 22. Charge \& Discharge Voltage $(\mathrm{Vg})$ and current $(\mathrm{Ig})(\mathrm{Vd}=23.9 \mathrm{kVpp})$

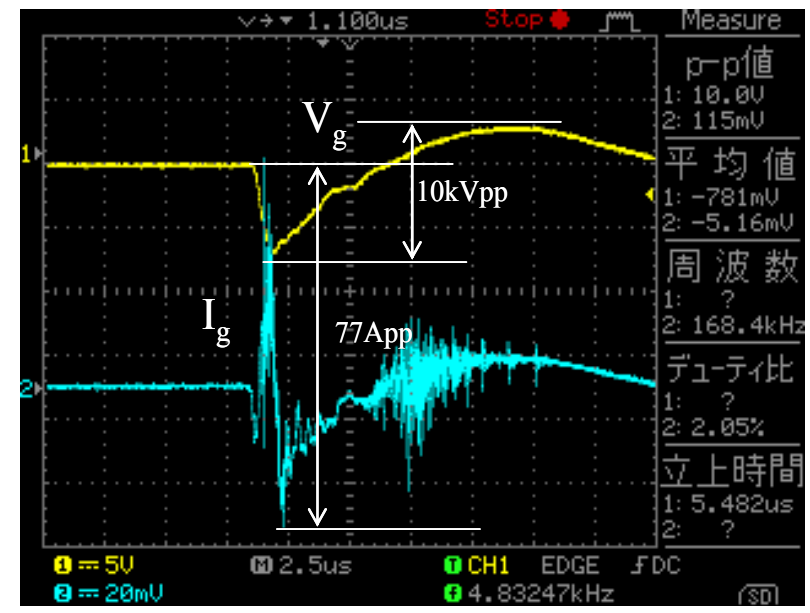

Figure 23. Detail of Figure $21(1 \mathrm{div} .=2.5 \mu \mathrm{s})$ 


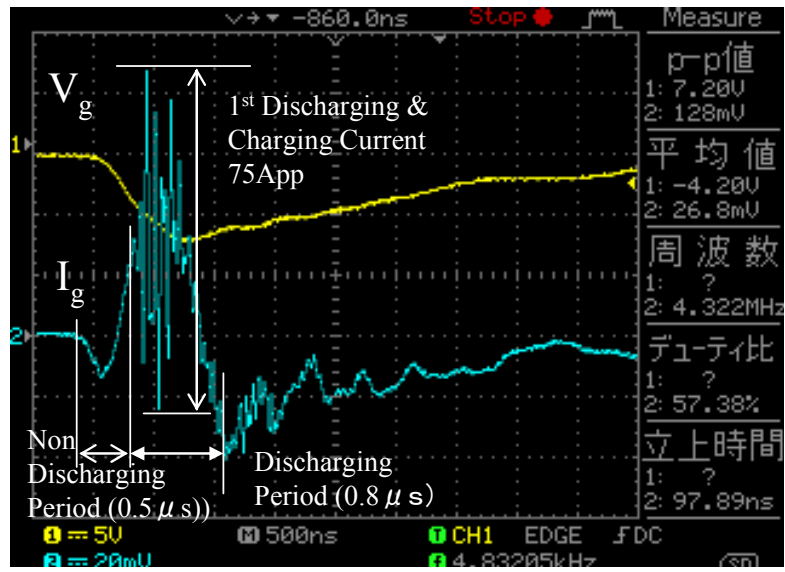

Figure 24. More detail of Figure 22. $(1 \mathrm{div} .=1.0 \mu \mathrm{s})$

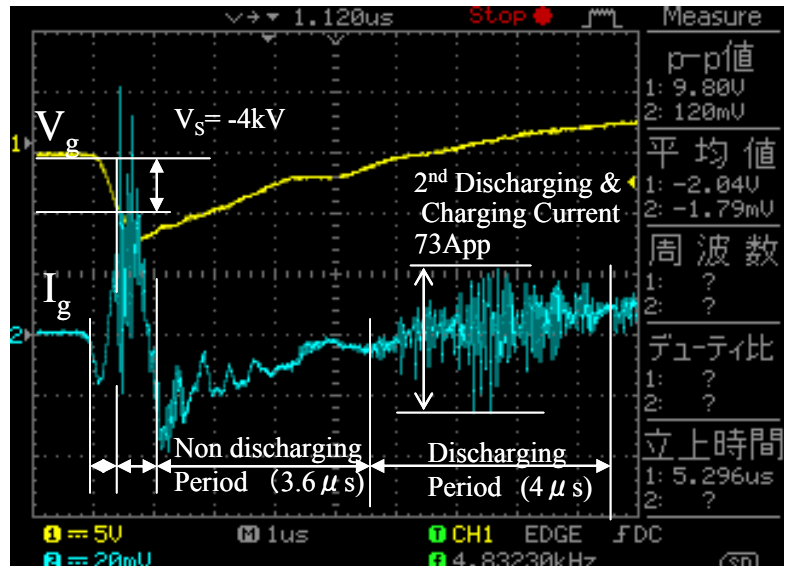

Figure 25. More detail of Figure 23. (1div. =500ns)

\subsection{Electric power consumption}

The average electric power consumption of the whole equipment including PPS unit and SDeDPF was calculated from the clamp current measurement value in the A section of Fig. 12. It has measured in the state of voltage $\mathrm{Vd}=23.9 \mathrm{kVpp}$ currently applied to SDeDPF. As an AC100V-50Hz was original power supply to PPS, the voltage of Ep=0.5 kV, $4.8 \mathrm{kHz}$. was setting in the PPS unit of this research.

As a result of measuring using final Ver. 6, the effective value voltage in Vrms $=100(\mathrm{~V})$ and clamp current measurement of the effective value current in the A section was $\mathrm{Irms}=0.88$ (A), and it turned out that effective (apparent) electric power (Pr) was 88(W).

On the other hand, as shown in Fig. 26, electric power consumption was calculated by the base of the coincidence measurement result of the voltage $(\mathrm{Vg})$ and the current $(\mathrm{Ig})$ of 
SdeDPF Ver. 6, when $\mathrm{Vd}=23.9 \mathrm{kVpp}$ was applied on it. Momentary power consumption (Wt) was calculated from multiplying current value (It) simultaneous by the voltage value (Vt) measured for every microsecond, the integrating amount of electric power consumption was divided by a cycle $\mathrm{T}=208 \mu \mathrm{s}$ and then average electric power consumption (Pr) was calculated like a formula (10) when expressed to the formula, and obtained the result of average electric power consumption $\operatorname{Pr}=90(\mathrm{~W})$ as shown in Fig. 27. In formula (13), they are $\mathrm{f}=4.8 \mathrm{kHz}, \mathrm{T}=208 \mu \mathrm{s}$, and $\mathrm{dt}=1 \mu \mathrm{s}$. Therefore, it becomes power consumption almost equivalent to the clamp current measurement result of $88(\mathrm{~W})$, and it can be said that the power consumption of the SDeDPF Ver.6 of this research is before and after 90 (W).

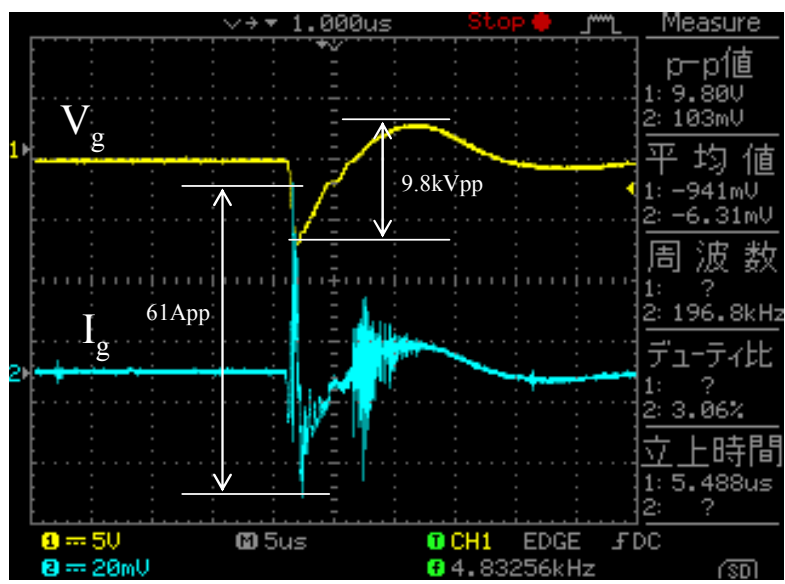

(Voltage (Vg), Current (Ig) at Vd $=23.9 \mathrm{kVpp}$ with Ver.6)

Figure 26. Base data for calculation of power consumption

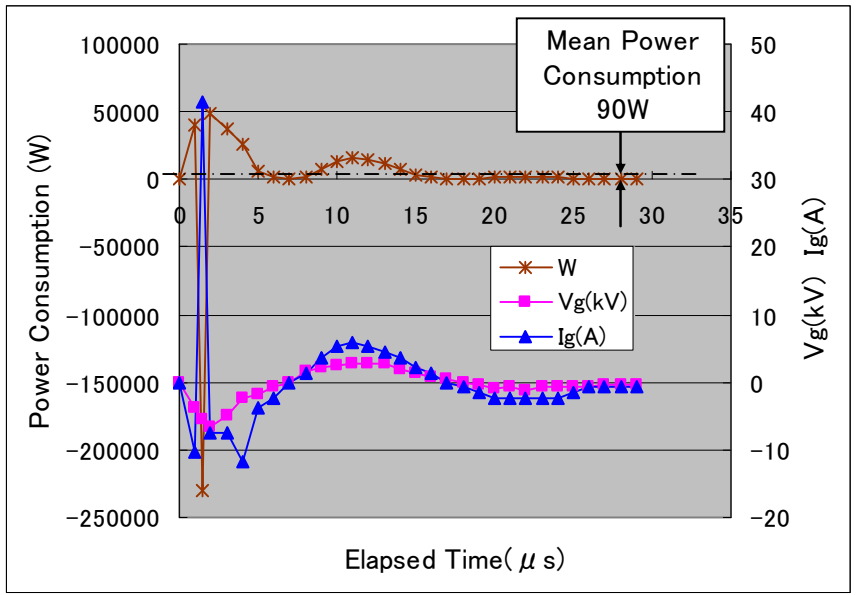

(Vd $=23.9 \mathrm{kVpp}$ with Ver.6)

Figure 27. Calculation result of power consumption 


$$
\operatorname{Pr}=\int_{0}^{T}\left(V_{t} \cdot I_{t} \cdot d t\right) / T
$$

\subsection{Evaluation result of PM removal}

Fig. 28 and 29 are PM removal quality assessment result under the room temperature and atmospheric pressure conditions of last specification Ver.6. SDeDPF was equipped as shown in Fig. 21, progress of PM concentration $\left(\# / \mathrm{cm}^{3}\right)$ change as opposed to changing the applied voltage by PPS unit was shown in Fig. 28. The relationship of PM concentration and distribution of the diameter of PM particle (Particle Size (nm)) in the stable point on each condition [1] to [6] of Fig. 28 are shown in Fig. 29. Supplied PM concentration ([1] PM Direct) from PM generating equipment is made into a starting point. It is the result of changing applied voltage and frequency in order of [3] to [6] after connecting SDeDPF to PM generating equipment ([2] Put ON; power supply OFF). At the condition [6] $\mathrm{Vd}$ $=23.9 \mathrm{kVpp}$, PM removal ratio of $95.6 \%$ is attained as opposed to the condition of the [2] power supply OFF.

Moreover, as shown in Fig. 29, sufficient reappearance has been checked from the repetition result of [6] power supply ON - [7] OFF - [6] ON - [7]OFF. Although in an early stage, $13.8 \%$ of PM adhesion in SDeDPF from the difference of the conditions [1] and [2] is checked, also after the condition [3], on while the voltage was impressed, it turned out that PM was removed continuously and efficiently even under room temperature and atmospheric pressure conditions. Although in Fig. 28, PM grain size distribution does not change a distribution state so much focusing on $100 \mathrm{~nm}$ of it, the absolute quantity of PM concentration is decreasing sharply.

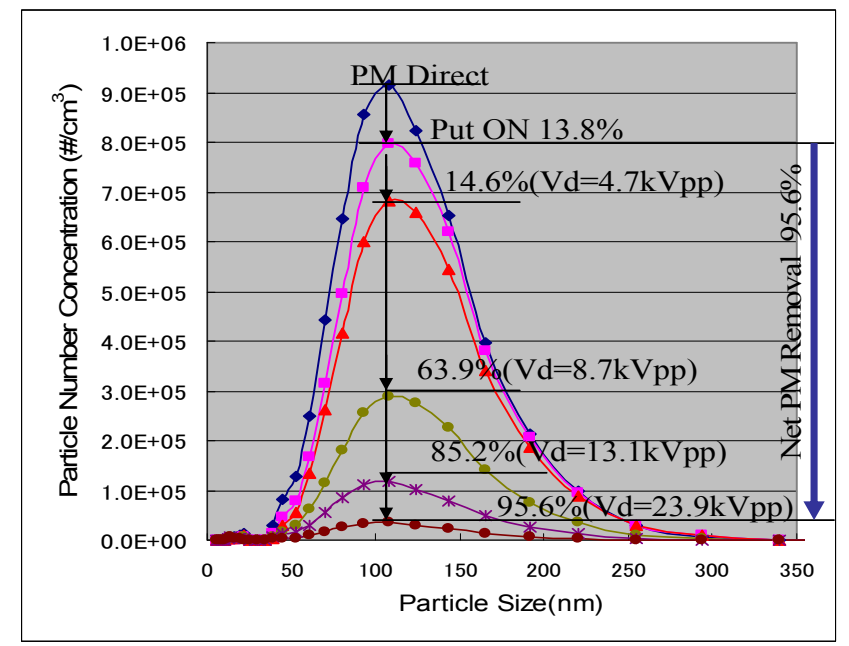

Figure 28. Elapsed Time of PM Removal by each Condition (Ver.6) 
In Fig. 30, it is the result of carrying out comparison arrangement of the PM removal performance of each specification to applied voltage Vd. Especially, Ver.6 with a turbulent flow block (T. B) have improved PM removal ratio of not less than $15 \%$ as opposed to nothing Ver5 mostly in all the voltage regions. The effect of T.B was checked certainly.

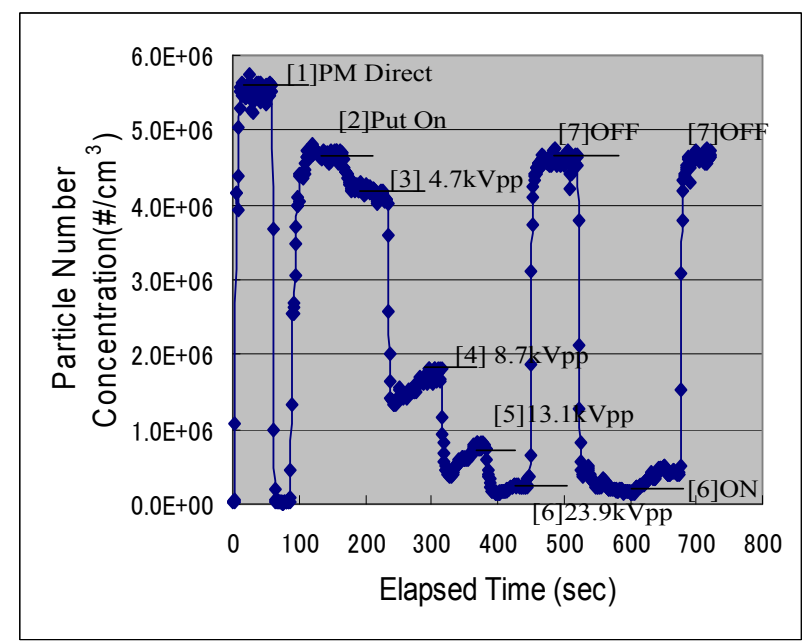

Figure 29. Particle Size Distribution at each Condition (ver.6)

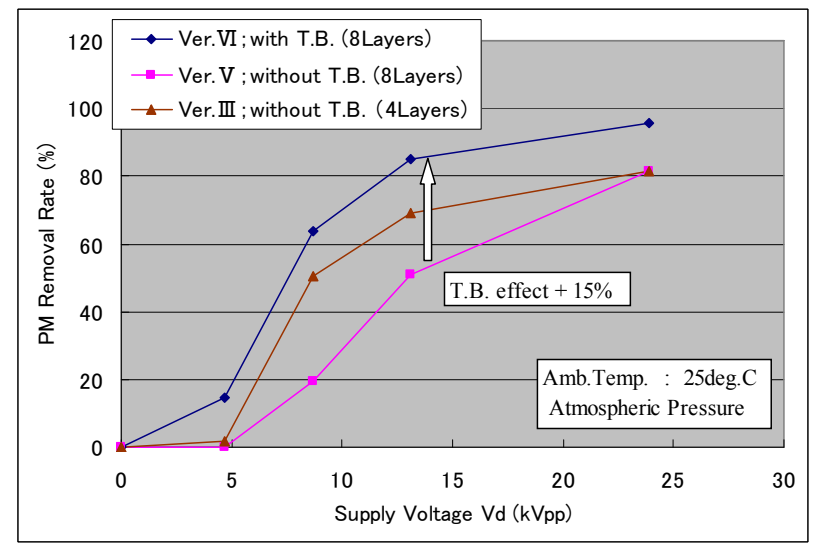

Figure 30. Effect of Turbulent Block for PM Removal 


\subsection{Relationship between PM removal quantity and pressure loss}

The horizontal axis of Fig. 31 is a pressure loss of SDeDPF which is measured by blower fan equipment. It is checked by $4 \mathrm{~m} \mathrm{3} / \mathrm{min}$ of air mass flow. Although the pressure loss of SDeDPF Ver.3 (4 Layers) which stacked four steps of basic cells was $5 \mathrm{kPa}$, the pressure loss of SdeDPF Ver.5 (8 Layers) which stacked eight steps of basic cells was about $1 \mathrm{kPa}$. As a result, it was set to one fifth and set to the level equivalent to the current ceramics DPF. And although SDeDPF Ver.6 added the Turbulent Block to Ver.5, since it was not the structure which closed a channel completely, it secured pressure loss almost equivalent to Ver.5. Ver.3 (4Layers) of pressure loss was decreased by 8 Layers which had twice about the passage cross-sectional area of exhaust gas and PM removal ratio was maintained by making equivalent electric field strength (total electric discharge area) with shortening electrode length from $\mathrm{L}=20 \mathrm{~mm}$ to $1 \mathrm{~mm}$ further. Furthermore, Ver.6 was added the Turbulent Block (T.B.) to the electric discharge space part of Ver.5, but the pressure loss was able to keep as almost equally and it was able to raise PM removal ratio from $81.35 \%$ to $95.6 \%$.

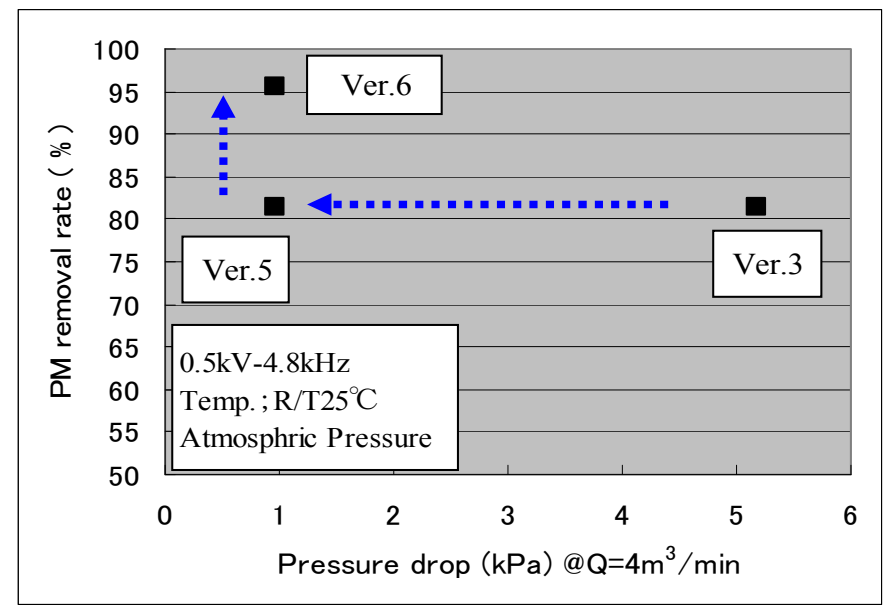

Figure 31. Relationship of PM Removal and Pressure Drop of SDeDPF

\subsection{Relationship between PM removal quantity and power consumption}

In Fig. 10, from the current measurement result of AC100V line with the clamp meter, when the voltage $23.9 \mathrm{kV}$ pp was applied on SDeDPF Ver.6, the electric power consumption of Ver. 6 was $88 \mathrm{~W}$. Moreover, from the current measurement result of having inserted $1.5 \Omega$ resistance in this line, it was $84 \mathrm{~W}$ as almost equally as the result of clamp meter. On the other hand, In PM removal evaluation of Fig. 28, the initial average number of PM concentration injected to SDeDPF Ver.6 was 5.5E+06 $\left(\# / \mathrm{cm}^{3}\right)$ and then it had been reduced to 
2.1E+05 $\left(\# / \mathrm{cm}^{3}\right)$ by passing through SDeDPF Ver.6 with electric discharge impressed $23.9 \mathrm{kV} p \mathrm{p}$ voltage. When these average number of PM concentration were converted into the PM weight concentration, it is equivalent to the quantity from $5616\left(\mu \mathrm{g} / \mathrm{m}^{3}\right)$ to $185\left(\mu \mathrm{g} / \mathrm{m}^{3}\right)$. Then the supplied gas flow rate was $25 \mathrm{~L} / \mathrm{min}\left(1.5 \mathrm{~m}^{3} / \mathrm{h}\right)$ which was containing PM from PM Generator. Therefore, the quantity: W of PM removed by electric discharge per hour $(\mathrm{g} / \mathrm{h})$ is set to following.

$$
\mathrm{W}=(5616-185) \times 1.5=8.15 \times 10^{-3}(\mathrm{~g} / \mathrm{h})
$$

Since power consumption is $84 \mathrm{w}$, the amount of PM removal (processing):W $\mathrm{W}_{1 \mathrm{kwh}}$ per $1 \mathrm{kwh}$ was set to following.

$$
\mathrm{W}_{1 \mathrm{kwh}}=8.15 \times 10^{-3} / 84 \times 10^{-3}=0.09(\mathrm{~g} / \mathrm{kWh})
$$

\section{Conclusion}

1. Silent Discharge type of electric DPF (SDeDPF) of this research is characterized by applying the unique MFS electrode and having Turbulent Brock in the lamination type of eight layers which has almost same exhaust pressure loss as current DPF made by ceramics. Finally, PM removal ratio of $95.6 \%$ has been attained with power saving of 84 to $90 \mathrm{~W}$ also under using no precious-metals, and room temperature and atmospheric pressure conditions.

2. Although the amount of PM removal (processing) per $1 \mathrm{kwh}$ became $0.09 \mathrm{~g} / \mathrm{kWh}$, the dielectrics used for SDeDPF of this research was a ceramic board which the dielectrics constant was $\varepsilon=8.5$, generally marketed in, cheap, and easy to come to hand. If the titanium dioxide $\left(\mathrm{TiO}_{2}\right) \varepsilon=86$ or barium titanate $\left(\mathrm{BaTiO}_{3}\right) \varepsilon=2900$ etc. were used, it was planed improvement in large electric field strength, and then the amount of PM removal might be further improvable.

I think that PM removal potential with SDeDPF in the minimum specification of a dielectric was able to be clarified this time.

\section{Author details}

Minoru Chuubachi and Takeshi Nagasawa Utsunomiya University, Japan

\section{References}

[1] Kanesaka H., Yoshiki H., Tanaka T., Akiba K., (2001) "Some Proposals to LowEmission, High-specific-Power Diesel Engine Equipped with CRT", SAE2001011256, pp.1-8 
[2] CRT, CCRT, "Large-sized Diesel Catalyst Division", Johnson Matthey, http://www.jmj.co.jp/diesel/crt.html , Accessed 2012 Mar. 28

[3] Daisho Y., (2006) "Recent Trends on Research and Development for Improving Motor Vehicle Exhaust Emission and Fuel Economy", Denso Technical Review, Vol.11, No.1, pp3-9

[4] Hori M., (2006) "Future Prospect of Eco-Diesel Engine", JSAE of Japan, Vol.60, No.9 (2006), pp.6-11

[5] Hirata K., Masaki N., Akagawa H., (2006) “The Urea-SCR System for Heavy-Duty Commercial Vehicle", JSAE of Japan, Vol.60, No.9, pp.28-33

[6] Chuubachi M., Nagasawa T., (2009) “Feasibility Study of a Silent Discharge Type of DPF Applied the Metal Fiber Sheet for an Electrode", Paper Book of JSAE KantouBlock Joint Lecture Meeting in 2009 Maebashi, OS0702, pp.3-4

[7] Chuubachi M., Nagasawa T., (2010) "Feasibility Study of a Silent Discharge Type of DPF without Precious Metal under Room Temperature and Atmospheric Pressure Condition", Transactions of the Japan Society of Mechanical Engineers B , Vol.76, No.772, pp.292-294

[8] Yukimura K., (2008) “Discharge Plasma Engineering”, EEText, First edition, IEEJ, pp.3233

[9] Yao S., (2009) "Plasma Reactors for Diesel Particulate Matter Removal”, Recent Patents on Chemical Engineering, No.2, pp.67-75

[10] Kim Y.H., et. Al, (2009) “Non-Thermal Plasma PM Removal System for Diesel Passenger Vehicles", JSAE Annual Congress (Fall), Proceedings, No.89-09, No.1220095727

[11] Kogelschatz U., (1999) "From Ozone Generators to Flat Television Screens: History and Future Potential of Dielectric-Barrier Discharges", Pure Apple. Chem., Vol. 71, No.10, pp.1819- 1828

[12] Harano A., (1998) “Oxidation of Carbonaceous Particles in Silent Discharge Reactor", Journal of Chemical Engineering of Japan, Vol.31, No.5, pp.700-705

[13] Yao S., (2007) “Comprephensive Technological Development of Innovative, Next-Generation, Low-Pollution Vehicles, Basic Study of PM Oxidation Promoted by $\mathrm{O}_{3}$ and $\mathrm{NO}_{2}$ “, JSAE Annual Congress (Fall), Proceedings, No.87-07, No.1220075799

[14] Tanaka S., Takakura S., Matsubara S., et. Al, (2006) "A Study on Low Temperature Oxidation of PM in Diesel Exhaustby using Non-thermal Plasma", Transaction of JSAE, Vol.37, No.6, pp.73-78

[15] Yukimura K., (2008) "Discharge Plasma Engineering", EEText, First edition, IEEJ, pp.132-137

[16] Tamita T., Iwata A., Tanaka M., “Discharge Measurement of ac Plasma Display panels using V-Q Lissajous Figure", IEEJ Transactions A, Vol.118, No.4, pp.353-358 
[17] Tanaka M., Yagi S., Tabata N., (1982) “Observation of Silent Discharge in Air" IEEJ Transactions A, Vol.102, No.10, pp. 9-16 